\title{
МРТ -ХАРАКТЕРИСТИКА И ИММУНОЛОГИЧЕСКИЕ ПАРАМЕТРЫ СОСТОЯНИЯ МИОКАРДА У ПАЦИЕНТОВ С АУТОИММУННЫМ ПОЛИГЛАНДУЛЯРНЫМ СИНДРОМОМ 2,3 ТИПОВ
}

\author{
Молашенко Н.В., Бабаева Д.М., Трошина Е.А., Александрова Е.Н., Новикова Д.С.
}

ЦЕЛЬ: оценка структуры и функционального состояния сердечной мышцы, оценка изменений спектра специфических аутоантител к миокарду у пациентов с аутоиммунным полигландулярным синдромом 2 , 3 типов.

МАТЕРИАЛЫ И МЕТОДЫ: работа проводилась в рамках гранта РНФ № 17-75-30035. В исследование включено 50 пациентов с доказанным аутоиммунным полигландулярным синдромом 2, 3 типов. 45 из них проведена MPT сердца с отсроченным контрастированием (MPT аппарат General Electric Optima MR450w 1.5 T (General Electric Healthcare, USA) контраст гадобутрол 1 ммоль/мл). Всем пациентам методом непрямого иммуноферментного анализа (ИФА) проведено определение антител $\lg G$ к антигенам сердечной мышцы, методом иммунохемилюминесцентного анализа (ИХЛА) - тропонина 1, натрийуретического пептида, методом NAC (N-ацетил-L-цистеин) - креатинфосфокиназы (KФК), методом иммунотурбидиметрии - С-реактивного белка (СРБ). Статистический анализ проводился на ПЭВМ с использованием пакета прикладных программ Statistica (StatSoft, USA, версия 13.3). Проверка на нормальность распределения данных выполнялась с помощью критерия Шапиро-Уилка. Для параметров с нормальным распределением рассчитывали среднюю величину (M) \pm стандартную ошибку средней $(\mathrm{m})$, количественные признаки, не имеющие приближенно нормального распределения, описывались в виде медианы и нижнего и верхнего квартилей, Ме [X1/4; X3/4].

РЕЗУЛЬТАТЫ: среди обследованных 50 пациентов (9 мужчин, 41 женщина) с АПС 2,3 типов, медиана возраста 39,5 [29; 53], у 45 (90\%) пациентов было сочетании первичной ХНН с другими аутоиммунными заболеваниями, у 5 (10\%) человек АПС протекал без первичной ХНH, 2 (4\%) пациента имели сопутствующие ревматологические заболевания. По результатам МРТ сердца, проведенного 45 из 50 пациентов, у 91\% пациентов выявлены признаки функциональных изменений миокарда левого желудочка, признаков перенесенного или текущего миокардита сердца не выявлено. У 38 из 45 обследованных определялось

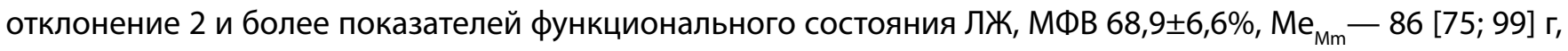
$\mathrm{Me}_{\text {уо }}-60,9[50 ; 66]$ мл, $\mathrm{Me}_{\text {кдои }}-52[44 ; 59] \mathrm{мл} / \mathrm{M}^{2}, \mathrm{Me}_{\text {ксои }}-17[15,3 ; 18] \mathrm{мл} / \mathrm{M}^{2}, \mathrm{Me}_{\text {ксо }}-26[23 ; 31] \mathrm{мл,}$ $\mathrm{Mе}_{\text {кдо }}-85[70 ; 92]$ мл.

По результатам определение АТ к антигенам сердечной мышцы - положительный результат выявлен у 1 пациента (2\%). У данного пациента имелось сочетания первичного XНH, первичного гипотиреоза и дерматомиозита.

Показатели тропонина 1 не превышали референсных значений. Уровень КФК превысил референсные значения у 3 пациентов (6\%), повышение СРБ, NT-proBNP отмечено у 7 пациентов (14\%), из них сочетанное повышение - в 1 случае.

ВЫВОды: у пациентов с АПС 2,3 типов получены МРТ-данные, свидетельствующие о функциональных изменениях миокарда. Аутоиммунная причина данных изменений по результатам определения АТ к миокарду не подтверждена у большинства обследованных пациентов, показатели «повреждения» миокарда (тропонин 1 и NT-proBNP) не имели отклонений от референсного диапазона. 